\title{
FITOSSOCIOLOGIA DO COMPONENTE ARBÓREO DE UM FRAGMENTO DE FLORESTA OMBRÓFILA MISTA ALUVIAL NO MUNICÍPIO DE GUARAPUAVA, PARANÁ
}

\author{
Thais Espinola de Oliveira Lima ${ }^{1}$, Roberto Tuyoshi Hosokawa ${ }^{2}$, Sebastião do Amaral Machado ${ }^{2}$
}

${ }^{1}$ Bióloga, Dr ${ }^{\mathrm{a}}$, Espinola \& Teixeira Advogados Associados S/C, Curitiba, PR, Brasil - toliveiralima@ gmail.com ${ }^{2}$ Eng. Florestal, Dr., Depto. de Ciências Florestais da UFPR, Curitiba, PR, Brasil - rth@japan.org.br; samachado@ufpr.br

Recebido para publicação: 21/10/2011 - Aceito para publicação: 14/08/2012

\begin{abstract}
Resumo
Este estudo é parte de uma pesquisa que envolve um fragmento de Floresta Ombrófila Mista Aluvial do rio das Mortes (bacia hidrográfica do rio das Pedras), município de Guarapuava (OLIVEIRALIMA, 2009), e analisa a composição florística e a estrutura fitossociológica do componente arbóreo da comunidade. Nas trinta e três parcelas contíguas de 10 × $20 \mathrm{~m}$ cada uma, foram inventariados (quanto à espécie, ao diâmetro à altura do peito (DAP) e à altura total) 1.047 indivíduos, com $\mathrm{DAP} \geq 4,8 \mathrm{~cm}$. Dentre as 39 espécies encontradas, a mais importante, com base no parâmetro valor de importância, foi Sebastiania commersoniana (Baill.) L.B.Sm. \& Dows (branquilho), que obteve os maiores valores de densidade e frequência. Contudo, os exemplares de maior porte na área são de Araucaria angustifolia (Bertol.) Kuntze (pinheiro-do-paraná), o que pode ser traduzido em razão de seu maior valor de dominância $\left(14,87 \mathrm{~m}^{2} \cdot \mathrm{ha}^{-1}\right)$. O valor obtido para o índice de diversidade de Shannon-Weaver foi de 2,2 nat/ind, e para o de equabilidade de Pielou foi de 0,6. A densidade total estimada foi de 1.586,36 indivíduos.ha ${ }^{-1}$, e os valores médios de DAP e altura encontrados foram $12,79 \mathrm{~cm}$ e $7,25 \mathrm{~m}$, respectivamente.

Palavras-chave: Floresta ripária; composição florística e estrutura; comunidade florestal.
\end{abstract}

\begin{abstract}
Phytosociology of tree component from a floodplain forest fragment, at Guarapuava, Paraná. This study is part of a research involving a Foodplain Forest fragment of rio das Mortes (rio das Pedras basin), municipality of Guarapuava (OLIVEIRA-LIMA, 2009) and analyze floristic composition and phytosociological structure of the arboreal component of the community. Within thirty-three 10 x 20 $\mathrm{m}$ contiguous plots it was evaluated (in relation to botanical species, Diameter at Base Height (DBH) and total height) 1047 individuals with $\mathrm{DBH} \geq 5 \mathrm{~cm}$. Among the 39 found species, the most important, accordingly to the parameter of importance value, was Sebastiania commersoniana (Baill.) L. B. Sm. \& Dows (branquilho), which reached the highest density and frequency values. However, the largest species are represented by Araucaria angustifolia (Bertol) Kuntze (Paraná - pine) which can be explained by its higher value of dominance $\left(14.87 \mathrm{~m}^{2} \cdot \mathrm{ha}^{-1}\right)$. The Shannon-Weaver diversity index value was 2.2 nat/ind and the equability index of Pielou was 0.6 . The total density stimated was $1,586.36$ individuals. ha ${ }^{-1}$ and the medium DBH and height was $12.79 \mathrm{~cm}$ and $7.25 \mathrm{~m}$, respectively. Keywords: Riparian Forest; Forest structure composition; forest community.
\end{abstract}

\section{INTRODUÇÃO}

A Floresta Ombrófila Mista (FOM), também conhecida como Floresta com Araucária (INSTITUTO BRASILEIRO DE GEOGRAFIA E ESTATÍSTICA (IBGE), 1992), encontra-se distribuída no Brasil meridional, principalmente na região Sul, abaixo do Trópico de Capricórnio, nos estados do Paraná, Santa Catarina e Rio Grande do Sul, e em áreas disjuntas nos estados de São Paulo, Rio de Janeiro e Minas Gerais (KLEIN, 1960; HUECK, 1972). Em função das variações altitudinais existentes nos domínios da Floresta Ombrófila Mista, ela pode ser subdividida, segundo IBGE (1992), nas formações Aluvial, Submontana, Montana e Altomontana. 
No Paraná, a Floresta com Araucária, que originalmente se apresentava com uma cobertura de $73.780 \mathrm{~km}^{2}$, ocupando $37 \%$ da área total do estado (MAACK, 2002), conta apenas com $0,8 \%$ de seus remanescentes naturais em estádio avançado de sucessão (FUNDAÇÃO DE PESQUISAS FLORESTAIS DO PARANÁ (FUPEF), 2001), distribuídos ao longo do primeiro e do segundo e na porção leste do terceiro planalto (REITZ; KLEIN, 1966).

Dentro desse contexto, mesmo as florestas aluviais responsáveis por importantes funções no ambiente, como manutenção da qualidade da água, estabilidade das margens, atenuação dos picos nos períodos de cheia, sustento para a fauna, formação de corredores, favorecendo a migração e a dispersão de animais e plantas, não escaparam de tal sorte, pois a deterioração desses ambientes, principalmente nas regiões mais populosas do Brasil, tem ocorrido em flagrante desrespeito à legislação. Os motivos para a retirada e/ou degradação dessa vegetação são diversos, indo desde os mais drásticos, como a construção de hidrelétricas e a expansão urbana e agrícola (DAVIDE; BOTELHO, 1999), até os mais sutis, porém não menos degradantes, como a extração de madeira, a carência de tratamentos de esgotos domésticos e industriais e a ausência de práticas adequadas e orientadas para o uso do solo (MEDRI et al., 2002).

Apesar de inúmeros trabalhos sistematizados de levantamento florístico e/ou fitossociológico terem sido realizados em áreas com FOM, ainda são necessários estudos dos remanescentes dessa unidade, principalmente com relação às espécies presentes, bem como a sua forma de distribuição na comunidade. Trabalhos dessa natureza não só contribuem para o conhecimento das características do local como também podem subsidiar diferentes tipos de projetos, como, por exemplo, os voltados para a melhoria da qualidade de vida das populações ribeirinhas.

Entre os trabalhos com enfoque qualitativo e/ou quantitativo, realizados em áreas de Floresta Ombrófila Mista Aluvial, no Paraná, podem-se citar os de Silva et al. (1992); Nakajima et al. (1996) e Dias et al. (1998), em florestas ripárias da bacia do rio Tibagi; Galvão et al. (1989) ao longo dos rios Anta e Imbituva, na Floresta Nacional de Irati; Moro et al. (2001) na bacia do rio São Jorge, em Ponta Grossa; Bufren (1997) nas margens do rio Pequeno, São José dos Pinhais; Silva et al. (1997) em área de várzea do rio Iguaçu, na região de São Mateus do Sul; Oliveira (2001); Souza (2001); Barddal (2002); Pasdiora (2003) e Curcio (2006) ao longo do rio Iguaçu.

Com a mesma finalidade, realizou-se o levantamento florístico e fitossociológico de um fragmento de Floresta Ombrófila Mista Aluvial em área de influência do rio das Mortes, na zona rural do município de Guarapuava. Foram objetivos do trabalho registrar as espécies constituintes do componente arbóreo e caracterizar a estrutura da floresta por meio do uso de parâmetros fitossociológicos usualmente utilizados como descritores da comunidade vegetacional. A área de estudo destaca-se em importância por representar um remanescente pouco antropizado da floresta ripária do rio das Mortes, principal tributário do rio das Pedras, que serve de manancial de abastecimento para o município de Guarapuava.

\section{MATERIAL E MÉTODO}

\section{Localização e caracterização da área de estudo}

A área estudada está situada no interior da propriedade do Sr. Alfredo Maniz, zona rural do município de Guarapuava, região centro-sul do Paraná, a um patamar altimétrico de 1.083 metros, entre as coordenadas $25^{\circ} 19^{\prime} 30^{\prime \prime}$ S e $51^{\circ} 23^{\prime} 55^{\prime \prime} \mathrm{W}$ (Figura 1 ).

O clima na região, segundo a classificação de Köppen, é do tipo $\mathrm{Cfb}$, com verões frescos e invernos com geadas. A pluviosidade mostra-se bem distribuída ao longo do ano, com precipitações médias em torno de $1.961 \mathrm{~mm} /$ ano e com uma temperatura média anual oscilando entre 16 e $17,5^{\circ} \mathrm{C}$ (THOMAZ; VESTENA, 2003).

O rio das Mortes, com seus $22 \mathrm{~km}$ de extensão, é o principal tributário da margem direita do rio das Pedras, que se constitui em fonte de abastecimento hídrico para o município de Guarapuava. Embora não tenha sido feita nenhuma compartimentação pedológica da área estudada, pode-se observar que alguns locais apresentavam um grau de saturação hídrica maior que outros. Essa variação, segundo Curcio et al. (2004), é determinante na paisagem, uma vez que as espécies se distribuem de acordo com o grau de hidromorfia dos solos.

Posteriormente, ao se realizar um levantamento, em pontos específicos, pode-se constatar que, de forma genérica, ocorrem na área dois tipos de solos: Cambissolos e Gleissolos.

A vegetação, classificada pelo IBGE (1992) como Floresta Ombrófila Mista Aluvial (floresta ripária, de galeria ou ciliar), está inserida na grande região da Estepe Gramíneo-Lenhosa do sul do Brasil, localmente denominada de Campos de Guarapuava, que, na área de estudo, está representada por um 
remanescente pouco antropizado, em meio a faxinais (modalidade regional de uso da terra constituída por terrenos justapostos de várias famílias que, de forma coletiva, ali criam seus animais à solta, em meio a áreas de vegetação, que também são utilizadas para extração de erva-mate). Segundo relato do filho do proprietário, há aproximadamente 45 anos, ocorreu o abate seletivo de árvores, especialmente araucária (Araucaria angustifolia) e imbuia (Ocotea porosa) no interior da propriedade (inclusive na área em estudo).

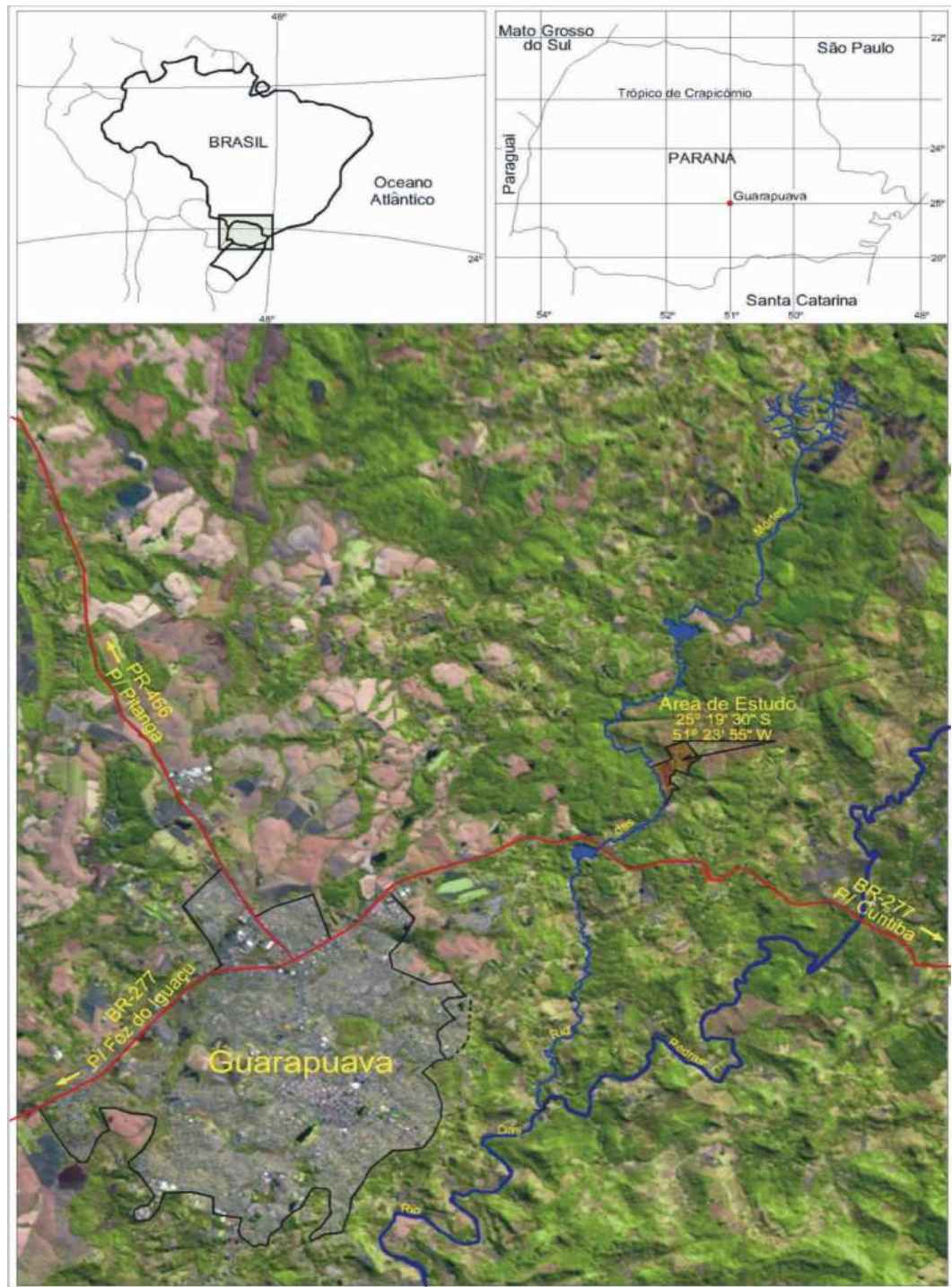

Figura 1. Imagem destacando a localização da área de estudo no estado do Paraná, no município de Guarapuava.

Figure 1. Image with detached spot of the focused area in Parana State, municipality of Guarapuava.

Até o início desta pesquisa (2005), o gado tinha acesso livre a todos os locais da propriedade. A partir de então, a área de floresta marginal foi isolada, mediante a construção de cercas.

\section{Procedimento metodológico}

Para o levantamento florístico e análise da estrutura fitossociológica, utilizou-se a metodologia

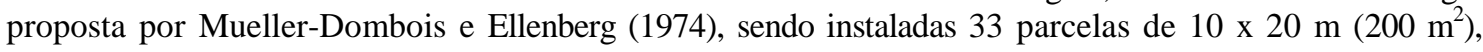
paralelas à margem esquerda do rio "e/ou" perpendiculares a este quando o traçado do mesmo exigia. 
Foram mensurados todos os indivíduos da parcela com perímetro à altura do peito (PAP) igual ou maior a $15 \mathrm{~cm}$ ou $4,8 \mathrm{~cm}$ de diâmetro à altura do peito (DAP). Cada indivíduo amostrado foi numerado, e em ficha de campo foram registradas as seguintes informações: nome "popular", PAP e altura total. Os indivíduos com múltiplos troncos se constituíram em amostras quando pelo menos um de seus troncos apresentou valor igual ou maior ao adotado. Árvores mortas, lianas e xaxins foram desconsiderados.

O material botânico de cada espécie coletada foi preparado de acordo com IBGE (1992) e incorporado ao Herbário do Colégio Florestal de Irati. A identificação das espécies foi feita mediante o uso de chaves analíticas, bibliografia especializada, comparações com exsicatas do herbário do curso de Engenharia Florestal da Universidade Federal do Paraná e consultas a especialistas. Os nomes das espécies foram verificados na Lista de Espécies da Flora do Brasil (2011), sendo utilizadas as abreviaturas dos autores sugeridas por Brummitt e Powell (1992).

Os dados obtidos foram digitados em software Excel for Windows para as devidas análises. Foram calculados os valores de densidade, dominância, frequência e valor de importância referentes à estrutura horizontal da comunidade em estudo. Os valores observados para os índices de diversidade de Shannon-Weaver (H') e de equabilidade de Pielou (J) foram obtidos segundo Magurran (1988).

Por meio de pesquisa bibliográfica, as espécies amostradas foram agrupadas quanto ao modo de dispersão de seus diásporos, tomando como parâmetro os estudos de Morellato e Leitão Filho (1992) e seguindo os critérios morfológicos propostos por Van der Pijl (1982).

\section{RESULTADOS E DISCUSSÃO}

Foram avaliados $6.600 \mathrm{~m}^{2}$ de área amostral, registrando-se 1.047 indivíduos, distribuídos em 39 espécies e 24 famílias botânicas (e uma não identificada), relacionadas em ordem alfabética (famílias/gêneros e espécies) na tabela 1. Ainda nessa tabela, com base em levantamento bibliográfico, foram registradas as formas de dispersão dos diásporos de cada uma das espécies amostradas.

Tabela 1. Composição florística (famílias e espécies) de um trecho de floresta aluvial do rio das Mortes, em Guarapuava - PR.

Table 1. Floristic composition (families and species) of a stretch of alluvial forest of rio das Mortes in Guarapuava - PR.

\begin{tabular}{|c|c|c|}
\hline Família/Espécie/Autor & Nome popular & $\begin{array}{c}\text { Forma de dispersão dos } \\
\text { diásporos }^{(1)}\end{array}$ \\
\hline \multicolumn{3}{|l|}{ Anacardiaceae } \\
\hline Schinus terebinthifolius Raddi & Aroeira & Zoocórica \\
\hline \multicolumn{3}{|l|}{ Aquifoliaceae } \\
\hline Ilex brevicuspis Reissek & Voadeira & Zoocórica \\
\hline Ilex dumosa Reissek & Caúna & Zoocórica \\
\hline Ilex paraguariensis A. St.-Hil. & Erva-mate & Zoocórica \\
\hline Ilex theezans Mart. ex Reissek & Orelha-de-mico & Zoocórica \\
\hline \multicolumn{3}{|l|}{ Araucariaceae } \\
\hline Araucaria angustifolia (Bertol.) Kuntze & Pinheiro-do-paraná & Zoocórica \\
\hline \multicolumn{3}{|l|}{ Asteraceae } \\
\hline Vernonanthura discolor (Spreng.) H.Rob. & Vassourão-preto & Anemocórica \\
\hline \multicolumn{3}{|l|}{ Bignoniaceae } \\
\hline Jacaranda micrantha Cham. & Caroba & Anemocórica \\
\hline \multicolumn{3}{|l|}{ Canellaceae } \\
\hline Cinnamodendron dinisii Schwacke & Pimenteira & Zoocórica \\
\hline \multicolumn{3}{|l|}{ Cannabaceae } \\
\hline Celtis iguanaea (Jacq.) Sarg. & Esporão-de-galo & Zoocórica \\
\hline \multicolumn{3}{|l|}{ Clethraceae } \\
\hline Clethra scabra Pers. & Carne-de-vaca & Zoocórica \\
\hline \multicolumn{3}{|l|}{ Erythroxylaceae } \\
\hline Erythroxylum deciduum A. St.- Hil. & Marmeleiro-bravo & Zoocórica \\
\hline
\end{tabular}




\begin{tabular}{|c|c|c|}
\hline \multicolumn{3}{|l|}{ Euphorbiaceae } \\
\hline Sapium glandullosum (L.) Morong & Leiteiro & Zoocórica \\
\hline $\begin{array}{l}\text { Sebastiania commersoniana (Baill.) L.B.Sm. \& } \\
\text { Dows }\end{array}$ & Branquilho & Outro \\
\hline \multicolumn{3}{|l|}{ Fabaceae } \\
\hline Erythrina falcata Benth. & Corticeira & Outro \\
\hline Mimosa scabrella Benth. & Bracatinga & Outro \\
\hline \multicolumn{3}{|l|}{ Lamiaceae } \\
\hline Vitex megapotamica (Spreng.) Moldenke & Tarumã & Zoocórica \\
\hline \multicolumn{3}{|l|}{ Lauraceae } \\
\hline Nectandra saligna & Canela & Zoocórica \\
\hline Ocotea puberula (Rich.) Ness & Canela-guaicá & Zoocórica \\
\hline Ocotea pulchella (Ness \&Mart.) Mez & Canela-do-brejo & Zoocórica \\
\hline \multicolumn{3}{|l|}{ Meliaceae } \\
\hline Cedrella fissilis Vell. & Cedro & Anemocórica \\
\hline \multicolumn{3}{|l|}{ Myrsinaceae } \\
\hline Myrsine coriacea (Sw.) R.Br. ex Roem. \& Schult. & Capororoquinha & Zoocórica \\
\hline \multicolumn{3}{|l|}{ Myrtaceae } \\
\hline Blepharocalyx salicifolius (Kunth) O. Berg. & Sapopema & Zoocórica \\
\hline Calyptranthes concinna DC. & Guamirim-ferro & Zoocórica \\
\hline Campomanesia xanthocarpa O.Berg. & Guabiroba & Zoocórica \\
\hline Eugenia pyriformis Cambess. & Uvaia & Zoocórica \\
\hline Myrceugenia euosma (O. Berg)D. Legrand & Guamirim-branco & Zoocórica \\
\hline Myrcia glabra (O. Berg) D. Legrand & Guamirim-vermelho & Zoocórica \\
\hline $\begin{array}{l}\text { Myrcianthes gigantea (D. Legrand)D. Legrand } \\
\text { Myrtaceae (ind. 1) }\end{array}$ & Cambuí & $\begin{array}{l}\text { Zoocórica } \\
\mathrm{NC}^{(2)}\end{array}$ \\
\hline Myrrhinium atropurpureum Schott & Murtilho & Zoocórica \\
\hline \multicolumn{3}{|l|}{ Quillajaceae } \\
\hline Quillaja brasiliensis (A.St.-Hil.\& Tul.) Mart & Saboneteira & Anemocórica \\
\hline \multicolumn{3}{|l|}{ Rosaceae } \\
\hline Prunus brasiliensis (Cham. \& Schltdl.)D. Dietr. & Pessegueiro-bravo & Zoocórica \\
\hline \multicolumn{3}{|l|}{ Rutaceae } \\
\hline Zanthoxylum rhoifolium Lam. & Mamica-de-cadela & Autocórica \\
\hline \multicolumn{3}{|l|}{ Salicaceae } \\
\hline Casearia decandra Jacq. & Guaçatunga-miúda & Zoocórica \\
\hline Xysloma pseudosalzmannii Sleumer & Sucareiro & Zoocórica \\
\hline \multicolumn{3}{|l|}{ Sapindaceae } \\
\hline $\begin{array}{l}\text { Allophylus edulis (A.St.-Hil.et al.) Hieron ex } \\
\text { Niederl. }\end{array}$ & Vacum & Zoocórica \\
\hline \multicolumn{3}{|l|}{ Solanaceae } \\
\hline Solanum pseudoquina A. St.-Hil. & Joazeiro & Zoocórica \\
\hline \multicolumn{3}{|l|}{ Symplocaceae } \\
\hline Symplocos uniflora (Pohl) Benth. & Maria-mole & Zoocórica \\
\hline \multicolumn{3}{|l|}{ Winteraceae } \\
\hline Drimys brasiliensis Miers & Cataia & Zoocórica \\
\hline Não identificada & & $\mathrm{NC}^{(2)}$ \\
\hline
\end{tabular}

Nota: (1) Dispersão dos diásporos: anemocórica (vento); zoocórica (animais); outros (autocórica, hidrocórica e barocórica).

(2) NC: não catalogada.

Devido à falta de material fértil entre as espécies listadas, uma delas foi identificada até o nível de família (Myrtaceae) e outra somente até o de divisão (Magnoliophyta).

Em termos de número de espécies, as famílias Myrtaceae (9), Aquifoliaceae (4), Lauraceae (3) e Euphorbiaceae, Fabaceae e Salicaceae (2 cada) foram as mais representativas, seguindo praticamente um padrão florístico para esse tipo de formação (PASDIORA, 2003; BARDDAL, 2002; OLIVEIRA, 2001; SOUZA, 2001; DIAS et al., 1998; NAKAJIMA et al., 1996). Cabe ressaltar, entretanto, que, embora não 
seja referência em termos de riqueza de espécies nos estudos citados anteriormente, a família Rosaceae, no presente trabalho, acabou se destacando, em razão da baixa variabilidade intraespecífica observada na área, pois, do total de famílias amostradas, $79 \%$ delas são representadas por uma única espécie. Essa prevalência de famílias monoespecíficas também foi observada por Barddal (2002) em um trecho de floresta aluvial em Araucária/PR (68,75\%).

Das 39 espécies vegetais amostradas, cerca de $76 \%$ delas possuem dispersão zoocórica de seus diásporos. Esse maior percentual também foi observado em vários estudos, entre os quais o de Moro et al. (2001), em uma área de floresta aluvial na região de Ponta Grossa (75\%), e o de Carmo e Morellato (2000), em matas ciliares da bacia do rio Tibagi (67,8\%), evidenciando a importância das florestas que margeiam os cursos de água não só para a manutenção dos corredores de fauna como também para a perpetuação da própria floresta.

Na tabela 2 são apresentados os resultados dos parâmetros fitossociológicos obtidos para as espécies amostradas, em ordem decrescente de valor de importância (VI).

Com uma densidade total estimada em 1.586,36 ind.ha ${ }^{-1}$, a referida tabela mostra que o fragmento apresenta Sebastiania commersoniana, conhecida popularmente pelo nome de branquilho, como espécie de maior VI, principalmente em razão de seus maiores valores de densidade e frequência. A capacidade do branquilho para adaptar-se às diferentes condições ambientais existentes na floresta ficou bem evidenciada, uma vez que ele ocorreu em todas as parcelas amostradas. Esse fato vem ao encontro das observações de Curcio et al. (2004) de que os indivíduos da espécie Sebastiania commersoniana ocorrem em solos com diferentes graus de hidromorfia.

Maior ocorrência do branquilho em florestas aluviais também foi observada por outros autores, entre os quais Klein e Hatschbach (1962), Oliveira (2001), Souza, 2001, Barddal (2002), Barddal et al. (2003), Pasdiora (2003) e Iurk (2008). No trabalho de Dias et al. (1998), em uma área de floresta aluvial do rio Iapó (bacia do rio Tibagi), entretanto, o branquilho não apresentou os maiores valores de importância, mas se destacou em número de indivíduos e em dominância.

As elevadas taxas de densidade $(39,83 \%)$ e dominância relativas $(32,46 \%)$ de S. commersoniana, espécie pertencente aos primeiros estágios sucessionais da floresta (CARVALHO, 2003), retratam a imaturidade desse fragmento.

Respondendo pelo segundo VI, aparece Araucaria angustifolia (pinheiro-do-paraná), que, embora apresente um valor de densidade bem menor do que o apresentado pelo branquilho, se destaca em razão de seu maior valor de dominância $\left(14,87 \mathrm{~m}^{2} / \mathrm{ha}\right)$. Apresentando os exemplares de maior porte na área (alturas entre 15 a 20 m), a araucária, ao contrário do que foi observado por Reitz e Klein (1966), Carvalho (2003) e Barddal (2006), se apresentou bem distribuída no local, estando presente em aproximadamente $82 \%$ das parcelas. Reconhecida como exigente quanto ao tipo de solo em que se desenvolve (REITZ; KLEIN, 1966), a araucária, no presente estudo, mostrou-se visivelmente raquítica apenas nas áreas mais abaciadas do terreno, pois nas partes mais altas da planície foram encontrados exemplares com diâmetros exuberantes representados na sua dominância relativa $(38,63 \%)$. Isso pode ser explicado em função da dinâmica do rio, que, ao modificar a paisagem, favorece a instalação de espécies mais seletivas nas porções mais altas, formadas por deposições alúvio-coluvionares. Ademais, o clima mais frio do sul, associado com as altitudes mais elevadas, podem estar favorecendo o predomínio da espécie também em áreas de florestas aluviais.

Espécie comum da floresta com araucária, Allophylus edulis (vacum) se diferencia das demais por ser uma das únicas desse bioma dotadas de folhas compostas, trifolioladas, com margem serreada. Apesar de seus exemplares apresentarem diâmetros bem menores (representados no seu valor de dominância) do que os apresentados pelas duas espécies anteriormente citadas, o vacum tem posição significativa em função da sua densidade (251,52 ind./ha) e frequência ( $94 \%$ das parcelas), atingindo um valor de VI de 32,83.

O Prunus brasiliensis (pessegueiro-bravo), que ocupa no ranking de VI o quarto lugar (25,64), é representado na área por árvores de porte mais avantajado que aquelas que ocupam o terceiro lugar. Distribuído em aproximadamente $76 \%$ das parcelas, o pessegueiro-bravo, em resposta às adversidades do ambiente, desenvolveu como estratégia de sobrevivência a produção de substâncias cianogênicas, se constituindo em uma espécie altamente tóxica para os animais (CARVALHO, 2003). Como, até o início do presente estudo, o gado tinha acesso livre ao local, isso explica a maior dominância relativa dessa espécie (7\%) em comparação com o vacum $(6,5 \%)$. 
Tabela 2. Estimativa dos parâmetros fitossociológicos das espécies arbóreas amostradas em um trecho de floresta aluvial no rio das Mortes, em ordem decrescente de valor de importância (VI).

Table 2. Estimate of phytosociological parameters from arboreal species sampled in a stretch of alluvial forest in rio das Mortes, in descending order of importance value (VI).

\begin{tabular}{|c|c|c|c|c|c|c|c|c|}
\hline Espécie & $\begin{array}{l}\mathrm{N}^{0} \text { de } \\
\text { indiv. }\end{array}$ & $\begin{array}{c}\text { DA } \\
\text { N/ha }\end{array}$ & $\begin{array}{c}\text { DoA } \\
\text { m }^{2} / \mathbf{h a}\end{array}$ & $\begin{array}{l}\text { FA } \\
(\%)\end{array}$ & $\begin{array}{l}\text { DR } \\
(\%)\end{array}$ & $\begin{array}{l}\text { DoR } \\
(\%)\end{array}$ & $\begin{array}{l}\text { FR } \\
(\%)\end{array}$ & VI \\
\hline Sebastiania commersoniana & 417 & 631,82 & 12,49 & 100,00 & 39,83 & 32,46 & 11,11 & 83,40 \\
\hline Araucaria angustifolia & 75 & 113,64 & 14,87 & 81,82 & 7,16 & 38,63 & 9,09 & 54,88 \\
\hline Allophylus edulis & 166 & 251,52 & 2,52 & 93,94 & 15,85 & 6,54 & 10,44 & 32,83 \\
\hline Prunus brasiliensis & 107 & 162,12 & 2,69 & 75,76 & 10,22 & 7,00 & 8,42 & 25,64 \\
\hline Ilex brevicuspis & 37 & 56,06 & 1,25 & 63,64 & 3,53 & 3,24 & 6,40 & 13,17 \\
\hline Zanthoxyllum rhoifolium & 42 & 63,64 & 0,52 & 57,58 & 4,01 & 1,35 & 7,07 & 12,43 \\
\hline Ilex paraguariensis & 48 & 72,73 & 0,61 & 51,52 & 4,58 & 1,59 & 5,72 & 11,89 \\
\hline Campomanesia xanthocarpa & 23 & 34,85 & 0,47 & 45,45 & 2,20 & 1,21 & 5,05 & 8,46 \\
\hline Symplocos uniflora & 12 & 18,18 & 0,29 & 27,27 & 1,15 & 0,75 & 2,67 & 4,57 \\
\hline Cinnamodendron dinisii & 11 & 16,67 & 0,16 & 24,24 & 1,05 & 0,42 & 3,03 & 4,50 \\
\hline Myrsine coriacea & 8 & 12,12 & 0,13 & 24,24 & 0,76 & 0,35 & 2,67 & 3,78 \\
\hline Eugenia pyriformis & 8 & 12,12 & 0,22 & 21,21 & 0,76 & 0,58 & 2,36 & 3,70 \\
\hline Ocotea pulchella & 9 & 13,64 & 0,18 & 21,21 & 0,86 & 0,47 & 2,36 & 3,69 \\
\hline Myrtacea indeterm. (1) & 7 & 10,61 & 0,17 & 21,21 & 0,67 & 0,44 & 2,36 & 3,47 \\
\hline Drimys brasiliensis & 9 & 13,64 & 0,21 & 15,15 & 0,86 & 0,54 & 1,68 & 3,08 \\
\hline Casearia decandra & 10 & 15,15 & 0,05 & 15,15 & 0,96 & 0,12 & 1,68 & 2,76 \\
\hline Myrcianthes gigantea & 5 & 7,58 & 0,18 & 12,12 & 0,48 & 0,46 & 1,35 & 2,29 \\
\hline Calyptrantes concina & 5 & 7,58 & 0,16 & 12,12 & 0,48 & 0,42 & 1,35 & 2,25 \\
\hline Schinus terebinthifolius & 4 & 6,06 & 0,15 & 12,12 & 0,38 & 0,39 & 1,35 & 2,12 \\
\hline Mimosa scabrella & 4 & 6,06 & 0,14 & 12,12 & 0,38 & 0,36 & 1,35 & 2,09 \\
\hline Ilex theezans & 5 & 7,58 & 0,05 & 12,12 & 0,48 & 0,12 & 1,35 & 1,95 \\
\hline Ilex dumosa & 4 & 6,06 & 0,04 & 12,12 & 0,38 & 0,11 & 1,35 & 1,84 \\
\hline Xylostoma pseudosalzmannii & 4 & 6,06 & 0,03 & 9,09 & 0,38 & 0,08 & 1,01 & 1,47 \\
\hline NI & 3 & 4,55 & 0,04 & 9,09 & 0,29 & 0,11 & 1,01 & 1,41 \\
\hline Ocotea puberula & 2 & 3,03 & 0,10 & 6,06 & 0,19 & 0,32 & 0,67 & 1,18 \\
\hline Celtis iguanaea & 3 & 4,55 & 0,06 & 6,06 & 0,29 & 0,17 & 0,67 & 1,13 \\
\hline Blepharocalix salicifolius & 2 & 3,03 & 0,09 & 6,06 & 0,19 & 0,24 & 0,67 & 1,10 \\
\hline Myrceugenia euosma & 2 & 3,03 & 0,05 & 6,06 & 0,19 & 0,13 & 0,67 & 0,99 \\
\hline Vitex megapotamica & 2 & 3,03 & 0,04 & 6,06 & 0,19 & 0,09 & 0,67 & 0,95 \\
\hline Clethra scabra & 2 & 3,03 & 0,03 & 6,06 & 0,19 & 0,07 & 0,67 & 0,93 \\
\hline Jacaranda micrantha & 1 & 1,52 & 0,16 & 3,03 & 0,10 & 0,42 & 0,34 & 0,86 \\
\hline Myrcia glabra & 1 & 1,52 & 0,16 & 3,03 & 0,10 & 0,42 & 0,34 & 0,86 \\
\hline Erythrina falcata & 1 & 1,52 & 0,08 & 3,03 & 0,10 & 0,21 & 0,34 & 0,65 \\
\hline Myrrhinium atropurpureum & 1 & 1,52 & 0,01 & 3,03 & 0,10 & 0,04 & 0,34 & 0,48 \\
\hline Quillaja brasiliensis & 1 & 1,52 & 0,01 & 3,03 & 0,10 & 0,03 & 0,34 & 0,47 \\
\hline Sapium glandulosum & 1 & 1,52 & 0,01 & 3,03 & 0,10 & 0,02 & 0,34 & 0,46 \\
\hline Vernonanthura discolor & 1 & 1,52 & 0,01 & 3,03 & 0,10 & 0,02 & 0,34 & 0,46 \\
\hline Erythroxyllum deciduum & 1 & 1,52 & 0,02 & 3,03 & 0,10 & 0,01 & 0,34 & 0,45 \\
\hline Nectandra saligna & 1 & 1,52 & 0,01 & 3,03 & 0,10 & 0,01 & 0,34 & 0,45 \\
\hline Solanum pseudoquina & 1 & 1,52 & 0,01 & 3,03 & 0,10 & 0,01 & 0,34 & 0,45 \\
\hline Cedrella fissilis & 1 & 1,52 & 0,01 & 3,03 & 0,10 & 0,01 & 0,34 & 0,45 \\
\hline TOTAL & 1047 & $1.586,36$ & 38,48 & 899,98 & 100,00 & 100,00 & 100,00 & 300,00 \\
\hline
\end{tabular}

Nota: $\mathrm{N}^{\mathrm{o}}$ de indiv.: número de indivíduos; DA: densidade absoluta; DR: densidade relativa; DoA: dominância absoluta; DoR: dominância relativa; FA: frequência absoluta; FR: frequência relativa; VI: valor de importância; "NI”: não identificada.

Em seguida aparece Ilex brevicuspis (voadeira), que, distribuída em aproximadamente $64 \%$ das parcelas, se sobressai em dominância $\left(1,25 \mathrm{~m}^{2}\right.$. ha $\left.{ }^{-1}\right)$ sobre as demais espécies com VI menores que 13,17. 
O perfil esquemático da área, retratando a dominância da araucária ( $1^{\circ}$ estrato) sobre um segundo estrato amplamente dominado pela Sebastiania commersoniana, Allophyllus edulis, Prunus brasiliensis e Ilex brevicuspis, encontra-se na figura 2.

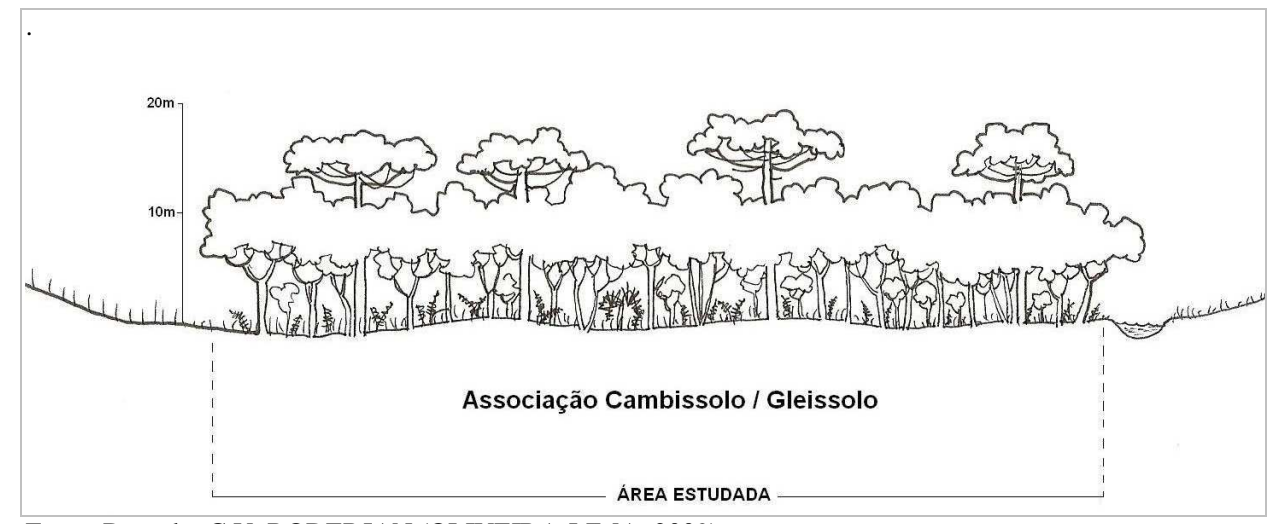

Fonte: Desenho C.V. RODERJAN (OLIVEIRA-LIMA, 2009).

Figura 2. Perfil esquemático de um trecho da FOM Aluvial na bacia do rio das Pedras.

Figure 2. Sketch profile of a stretch of Alluvial FOM in rio das Pedras watershed.

Aparecendo frequentemente em clareiras de florestas primárias e em diferentes estágios da sucessão secundária (LORENZI, 2002), Zanthoxyllum rhoifolium (mamica-de-cadela) é a sexta espécie que se destaca em termos de VI $(12,43)$ no fragmento. Espécie característica da FOM, sempre em associações nitidamente evoluídas com Araucaria angustifolia (CARVALHO, 2003), Ilex paraguariensis (erva-mate) responde pelo sétimo VI $(11,89)$. Distribuída em mais de 50\% das parcelas, é representada no presente estudo por árvores de pequenas dimensões, que se traduz no baixo valor de dominância apresentado $\left(0,61 \mathrm{~m}^{2} \cdot \mathrm{ha}^{-1}\right)$. A situação de estresse a que essas árvores são submetidas, anualmente, por ocasião da retirada de suas folhas, destinadas à indústria da erva, pode explicar as pequenas dimensões observadas. A partir do oitavo VI, a frequência foi um fator importante, pois indica um certo gregarismo entre as espécies, já que muitas delas estão concentradas em poucas parcelas. Além disso, $77,5 \%$ das espécies amostradas possuem densidade relativa inferior a $1 \%$, indicando que elas possuem uma representatividade baixa na área.

O valor estimado para o índice de diversidade de Shannon foi de 2,2 nat/ind. Esse valor, que se mostra mais baixo do que o encontrado por Nakajima et al. (1996) em um fragmento de floresta ripária na bacia do rio Tibagi $\left(\mathrm{H}^{\prime}=3,61\right)$ e por Moro et al. (2001) em uma área de mata ciliar do rio Cará-Cará, em Ponta Grossa $\left(\mathrm{H}^{\prime}=2,97\right)$, é comum nos remanescentes de FOM que se encontram em áreas de maior altitude, onde os rigores do clima exercem pressão seletiva sobre a diversidade vegetal (RODERJAN et al., 2002).

No caso do índice de equabilidade de Pielou, o valor de 0,6 obtido mostra que não existe uma distribuição uniforme entre número de indivíduos e de espécies. Fato esse que fica evidente com relação à espécie Sebastiania commersoniana, que responde por $40 \%$ do total dos indivíduos da amostra.

Os valores médios de altura e de DAP dos exemplares das espécies estudadas foi, respectivamente, de $7,25 \mathrm{~m}$ e de $12,79 \mathrm{~cm}$.

A distribuição diamétrica dos indivíduos presentes no fragmento estudado (Figura 3) segue o padrão observado nas florestas naturais heterogêneas e multietâneas (MACHADO et al., 1987), ou seja, apresenta uma distribuição exponencial na forma de "J" invertido. Isso aponta para um bom desenvolvimento da floresta, com muitos representantes nas primeiras classes, havendo uma diminuição gradativa conforme o aumento de diâmetro. Esse tipo de distribuição, segundo Longhi (1980), garante que o processo dinâmico da floresta se perpetue.

Embora não tenha feito parte do material amostrado, verificou-se na área em estudo a presença de espécies epifíticas, com destaque para as Bromeliáceas e Pteridophytas. Também na área foram observados exemplares de Dicksonia sellowiana (xaxim) e de lianas, geralmente ocupando estratos superiores. 


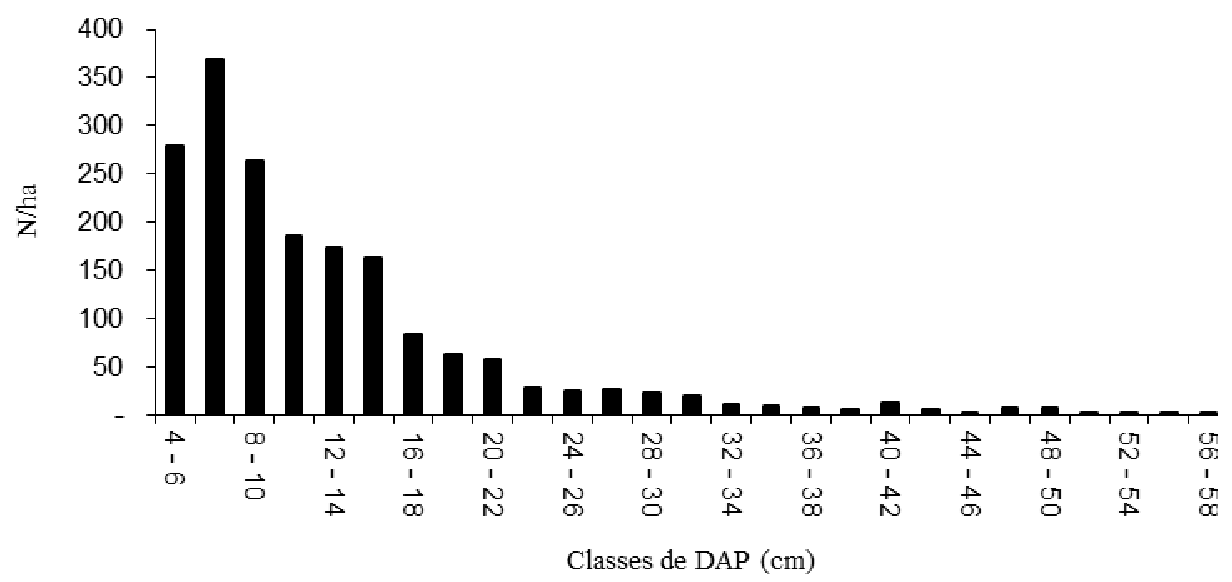

Figura 3. Distribuição por classe de DAP dos indivíduos amostrados no fragmento de FOM aluvial no rio das Mortes, Guarapuava/PR.

Figure 3. DBH classes of individuals sampled in the stretch of alluvial FOM in rio das Mortes, Guarapuava/PR.

\section{CONCLUSÕES}

Com base nos resultados obtidos, é possível concluir que:

- o fragmento estudado é um importante remanescente de Floresta Ombrófila Mista Aluvial, em meio a faxinais;

- a formação encontra-se pouco antropizada, apresentando as famílas Myrtaceae, Aquifoliaceae, Lauraceae, Euphorbiacea, Fabaceae e Salicaceae como as mais representativas em termos de número de espécies;

- Sebastiania commersoniana, por ter atingido o mais alto valor de importância, em razão de seus valores de densidade $\left(631,82\right.$ ind.ha $\left.^{-1}\right)$ e frequência (100\%), pode ser enquadrada como a principal espécie arbórea desse fragmento;

- Araucaria angustifolia se destacou em razão de seu valor de dominância, apresentando os exemplares de maior porte na área. Também se destacaram no fragmento estudado Allophylus edulis e Prunus brasiliensis;

- o maior percentual de espécies com dispersão zoocórica de seus diásporos reforça a importância de se preservar a floresta aluvial para a manutenção dos corredores de fauna, e destes para a perpetuação da própria floresta;

- os baixos valores observados para os índices de diversidade de Shannon e de Pielou mostram que não existe uma distribuição uniforme entre número de indivíduos e número de espécies na área em estudo.

- o remanescente de FOM Aluvial do rio das Mortes encontra-se em estágio médio de sucessão natural.

\section{AGRADECIMENTOS}

Ao professor Ronald Medeiros, Sr. Augusto Andreola, ao acadêmico Fábio Gaffke e ao Instituto Ambiental do Paraná (unidade Guarapuava), pela colaboração no trabalho de campo.

Ao Fábio Solter, engenheiro florestal que disponibilizou o Programa STRUCT.bas para o cálculo dos índices fitossociológicos. 


\section{REFERÊNCIAS}

BARDDAL, M. L. Aspectos florísticos e fitossociológicos do componente arbóreo-arbustivo de uma Floresta Ombrófila Mista Aluvial - Araucária, PR. 83 f. Dissertação (Mestrado em Engenharia Florestal) - Setor de Ciências Agrárias, Universidade Federal do Paraná, Curitiba, 2002.

A influência da saturação hídrica na distribuição de oito espécies arbóreas da Floresta Ombrófila Mista Aluvial do rio Iguaçu, Paraná, Brasil. 230 f. Tese (Doutorado em Engenharia Florestal) - Setor de Ciências Agrárias, Universidade Federal do Paraná, Curitiba, 2006.

BARDDAL, M. L.; PROTIL, C. Z.; SOUZA, S. G. A. Fitossociologia do componente arbóreo de um trecho de planície do rio Iraizinho, Piraquara, Paraná, Brasil. Revista de Estudos de Biologia, Curitiba, v. 25 , n. 53 , p. $17-28$, out./dez. 2003.

BRUMMITT, R. K.; POWELL, C. E. Authors of plant names. Kew: Royal Botanic Gardens, 1992.

BUFREN, A. M. Caracterização fitossociológica de um remanescente da floresta ripária do rio Pequeno, São José dos Pinhais, PR. 87 f. Dissertação (Mestrado em Botânica) - Setor de Ciências Biológicas, Universidade Federal do Paraná, Curitiba, 1997.

CARMO, M. R. B.; MORELLATO, L. P. C. Fenologia de árvores e arbustos das matas ciliares da bacia do rio Tibagi, Estado do Paraná, Brasil. In: RODRIGUES, R. R.; LEITÃO FILHO, H. F. (eds.). Matas ciliares: conservação e recuperação. São Paulo: EDUSP/FAPESP, 2000. p. 125 - 141.

CARVALHO, P. E. R. Espécies arbóreas brasileiras. Brasília, DF: Embrapa Informação Tecnológica; Colombo: Embrapa Florestas, 2003.

CURCIO, G. R. Caracterização geológica, pedológica e fitossociológica do rio Iguaçu Paraná Brasil. 500 f. Tese (Doutorado em Engenharia Florestal) - Setor de Ciências Agrárias, Universidade Federal do Paraná, Curitiba, 2006.

CURCIO, G. R.; BONNET A.; BARDDAL, M. L. A floresta em ambientes fluviais. Guia dirigido. Colombo: EMBRAPA, 2004. 9 p.

DAVIDE, A. C.; BOTELHO, S. A. Análise crítica dos programas de recomposição de matas ciliares em Minas Gerais. In: SIMPÓSIO SOBRE MATA CILIAR: CIÊNCIA E TECNOLOGIA, 1999, Lavras. Anais... Lavras: Gráfica da Universidade Federal de Lavras, 1999. p. 172 - 188.

DIAS, M. C.; VIEIRA, A. O. S.; NAKAJIMA, J. N.; PIMENTA, J. A.; LOBO, P. C. Composição florística e fitossociológica do componente arbóreo das florestas ciliares do rio Iapó, na bacia do rio Tibagi, Tibagi, PR. Revista Brasileira de Botânica, São Paulo, v. 21, n. 2, p. 1 - 15, 1998.

FUNDAÇÃO DE PESQUISAS FLORESTAIS DO PARANÁ (FUPEF). Conservação do bioma floresta com araucária: relatório final: diagnóstico dos remanescentes florestais. Curitiba: FUPEF, 2001. $2 \mathrm{v}$.

GALVÃO, F.; KUNIYOSHI, Y. S.; RODERJAN, C. V. Levantamento fitossociológico das principais associações arbóreas da Floresta Nacional de Irati - PR. Revista Floresta, Curitiba, v. 19, n. 1 - 2, p. 30 40, 1989.

HUECK, K. As florestas da América do Sul: ecologia, composição e importância econômica. Tradução: Hans Reichardt. São Paulo: Edusp, 1972. 466 p.

INSTITUTO BRASILEIRO DE GEOGRAFIA E ESTATÍSTICA (IBGE). Manual técnico da vegetação brasileira. Rio de Janeiro: Fundação Instituto Brasileiro de Geografia e Estatística, 1992. 92 p. (Manuais Técnicos de Geociências n. 1).

IURK, M. C. Levantamento florístico de um fragmento de Floresta Ombrófila Mista Aluvial do rio Iguaçu, município de Palmeira - PR. 102 f. Dissertação (Mestrado em Botânica) - Setor de Ciências Biológicas, Universidade Federal do Paraná, Curitiba, 2008. 
KLEIN, R. M. O aspecto dinâmico do pinheiro brasileiro. Sellowia, Itajaí, n. 12, p. 17 - 44, 1960.

KLEIN, R. M.; HATSCHBACK, G. Fitofisionomia e notas para acompanhar a planta fitogeográfica do Município de Curitiba e arredores - Paraná. Boletim da Universidade do Paraná. Geografia Física, Curitiba, n. 4, p. 1 - 29, dez., 1962.

Lista de Espécies da Flora do Brasil 2011. In: 〈http://floradobrasil.jbrj.gov.br/2011〉.

LONGHI, S. J. A estrutura de uma floresta natural de Araucaria angustifolia (Bert.) O. Ktze, no Sul do Brasil. 198 f. Dissertação (Mestrado em Engenharia Florestal) - Setor de Ciências Agrárias, Universidade Federal do Paraná, Curitiba, 1980.

LORENZI, H. Árvores brasileiras: manual de identificação e cultivo de plantas arbóreas do Brasil. São Paulo: Nova Odessa: Instituto Plantarum, 2002. 382 p.

MAACK, R. Geografia física do estado Paraná. 3. ed. Curitiba: Imprensa Oficial, 2002. 450 p.

MACHADO, S. A.; BARTOSZEK, A. C. P. S.; OLIVEIRA, E. B. de. Estudo da estrutura diamétrica para Araucaria angustifolia em florestas naturais nos estados da região Sul do Brasil. Floresta, Curitiba, v. 1/2, n. 26, p. 59, 1987.

MAGURRAN, A. E. Ecological diversity and its measurement. New York: Chapman and Hall, 1988. $179 \mathrm{p}$.

MEDRI, M. E.; BIANCHINI, E.; PIMENTA, J. A.; COLLI, S.; MÜLLER, C. Estudos sobre tolerância ao alagamento em espécies arbóreas nativas da bacia do rio Tibagi. In: MEDRI, M. E.; BIANCHINI, E.; SHIBATTA, O. A.; PIMENTA, J. A. A bacia do rio Tibagi. Londrina: Copyright, 2002. p. 133 - 172.

MORELLATO, L. P. C.; LEITÃO-FILHO, H. F. Padrões de frutificação e dispersão na Serra do Japi. In: MORELlATO, L. P. C. (ed.). História natural da Serra do Japi: ecologia e preservação de uma área florestal no Sudeste do Brasil. Campinas: Ed. UNICAMP, 1992. p. 112 - 140.

MORO, R. S.; SMITH, J.; DIEDRICHS, L. A. Estrutura de um fragmento da mata ciliar do rio CaraCará, Ponta Grossa, PR. Publication UEPG, Ponta Grossa, v. 1, n. 1, p. 19 - 38, 2001.

MUELLER-DOMBOIS, D.; ELLENBERGER, H. Aims and methods of vegetation ecology. New York: John Wiley \& Sons, 1974. 547 p.

NAKAJIMA, J. N.; SOARES-SILVA, L. H.; MEDRI, M. E.; GOLDENBERG, R.; CORREA, G. T. Composição florística e fitossociologia do componente arbóreo das florestas ripárias da bacia do rio Tibagi: 5. Fazenda Monte Alegre, município de Telêmaco Borba, Paraná. Arquivos de Biologia e Tecnologia (TECPAR), v. 39, n. 4, p. 933 - 948, 1996.

OLIVEIRA, E. A. Caracterização florística, fitossociológica e pedológica de um trecho de floresta ripária dos Campos Gerais do Paraná. 106 f. Dissertação (Mestrado em Engenharia Florestal) - Setor de Ciências Agrárias, Universidade Federal do Paraná, Curitiba, 2001.

OLIVEIRA-LIMA, T. E. Análise fitossociológica da macrofauna edáfica e da biomassa em um trecho de floresta ripária no Município de Guarapuava, Paraná. 130 f. Tese (Doutorado em Engenharia Florestal) - Setor de Ciências Agrárias, Universidade Federal do Paraná, Curitiba, 2009.

PASDIORA, A. L. Florística e fitossociologia de um trecho de floresta ripária em dois compartimentos ambientais do rio Iguaçu, Paraná, Brasil. 47 f. Dissertação (Mestrado em Engenharia Florestal) - Setor de Ciências Agrárias, Universidade Federal do Paraná, Curitiba, 2003.

REITZ, R.; KLEIN, R. M. Araucariaceae. In: REITZ, R. (ed.). Flora Ilustrada Catarinense. Itajaí: Herbário Barbosa Rodrigues, 1966. 29 p.

RODERJAN, C. V.; GALVÃO, F.; KUNIYOSHI, Y. S.; HATSCHBACH, G. G. As unidades fitogeográficas do estado do Paraná. Ciência e Ambiente, Santa Maria, v. 24, p. 75 - 92, 2002. 
SILVA, S. M.; BRITEZ, R. M. de; SOUZA, W. S. de; MOTTA, J. T. Levantamento florístico em área de várzea do rio Iguaçu, São Mateus do Sul - PR - Brasil. Arquivos de Biologia e Tecnologia, v. 40, n. 4, p. $903-913,1997$.

SILVA, S. M.; SILVA F. C.; VIEIRA, A. O. S.; NAKAJIMA, J. N.; PIMENTA, J. A.; COLLI, S. Composição florística e fitossociologia do componente arbóreo das florestas ciliares da bacia do rio Tibagi. 1. Várzea do rio Bitumirim, município de Ipiranga, PR. Revista do Instituto Florestal, v. 4, p. $192-198,1992$.

SOUZA, M. K. F. Florística e fitossociologia do estrato arbóreo-arbustivo de diferentes compartimentos em ambiente fluvial no município de Jaguariaíva, Paraná. $108 \mathrm{f}$. Dissertação (Mestrado em Botânica) - Setor de Ciências Biológicas, Universidade Federal do Paraná, Curitiba, 2001.

THOMAZ, E. L.; VESTENA, L. R. Aspectos climáticos de Guarapuava - PR. Guarapuava: Editora UNICENTRO, 2003. $106 \mathrm{p}$.

VAN DER PIJL, L. Principles of dispersal in higther plants. 3. ed. New York: Springer-Verlag, 1982. $215 \mathrm{p}$. 